\title{
Pulmonary endarterectomy and the cost of patient refusal
}

\author{
Nick H. Kim ${ }^{1}$ and Eckhard Mayer ${ }^{2}$ \\ Affiliations: ${ }^{1}$ Pulmonary and Critical Care Medicine, University of California San Diego, La Jolla, CA, USA. \\ ${ }^{2}$ Thoracic Surgery, Kerckhoff Clinic Heart and Lung Centre, Bad Nauheim, Germany.
}

Correspondence: Nick H. Kim, Pulmonary and Critical Care Medicine, University of California San Diego, 9300 Campus Point Drive, MC 7381, La Jolla, CA 92037, USA. E-mail: h33kimवucsd.edu

@ERSpublications

The recommended treatment for operable chronic thromboembolic pulmonary hypertension is pulmonary endarterectomy, and patients who refused surgery in the current study had worse longterm survival than those who underwent surgery http://ow.ly/WJ0P30lBxY9

Cite this article as: Kim NH, Mayer E. Pulmonary endarterectomy and the cost of patient refusal. Eur Respir J 2018; 52: 1801581 [https://doi.org/10.1183/13993003.01581-2018].

Without effective treatment, patients with chronic thromboembolic pulmonary hypertension (CTEPH) will struggle and ultimately die of right heart failure [1]. The key pathological features of CTEPH consist of obstructive chronic thrombi (resistant to thrombolysis and despite adherence to anticoagulation) in the proximal elastic pulmonary arteries combined with varying degrees of microvascular remodelling $[2,3]$. Both processes contribute to pulmonary hypertension, but the successful removal of the proximal mechanical component with pulmonary endarterectomy (PEA) often leads to dramatic improvement in pulmonary hypertension with improved quality of life and better long-term survival [4-6]. Accordingly, the treatment of choice for patients suffering from CTEPH remains PEA to remove all accessible obstructive disease within the pulmonary arteries thereby improving pulmonary circulation [5, 7]. The report by QUADERY et al. [8] in this issue of the European Respiratory Journal is a timely reminder regarding the importance and benefits of PEA, and the risk patients take when an offer of PEA is refused.

Patients with CTEPH face numerous hurdles. First, the diagnosis is often delayed for months or years [9]. Once proper diagnosis is made, many patients are not referred for surgical consideration due to a combination of reasons including providers having misinformation or general lack of treatment awareness [10]. Many patients around the globe also simply do not have access to a qualified surgical centre. Even in Europe and the USA, with fewer issues with centre access, a survey reported only $10-15 \%$ of CTEPH cases ultimately undergo PEA [10]. Although that report may have been biased by surveying providers treating CTEPH patients with medical therapy, the message all the same is still clear: too many patients are not receiving this potentially life-saving surgery. This underscores the next hurdle after centre access: the question of operability and suitability for PEA. In the international CTEPH registry (Europe and Canada), up to $40 \%$ of evaluated CTEPH cases were deemed to be inoperable. In that registry, patients who underwent PEA had a 3-year survival of $89 \%$, compared to $70 \%$ for those not operated on (hazard ratio 0.37, 95\% CI 0.24-0.58; $\mathrm{p}<0.0001$ ) [11]. Although long-term differences in quality of life and functional capacity were not reported, by the 1-year assessment the majority of operated patients achieved functional class I or II status (from III and IV pre-PEA), and the median 6-min walk distance (6MWD) increased from $362 \mathrm{~m}$ to $459 \mathrm{~m}$ [5]. These and numerous other reports underscore the reason PEA is the recommended treatment in guidelines for operable CTEPH [7]. 
In the study by QUADERY et al. [8], the prospective registry from Sheffield (UK) reported on 550 consecutive CTEPH patients enrolled from 2001 to 2014. A multidisciplinary team reviewed each case, with suitability for PEA being assessed remotely by an experienced surgeon at the national reference PEA centre, Papworth Hospital (Cambridge, UK). Overall, 50\% $(n=278)$ were determined not to be candidates for PEA. $37 \%$ of those cases ( $n=102,18 \%$ of total) were deemed to have disease not amenable to surgery: either disease felt to be too distal following evaluations or pulmonary hypertension out of proportion to apparent accessible disease burden. These cases on average were more likely to be female (62\%, versus $45 \%$ for those operated) and older (age 65 years, versus 58 years for those operated) and have lower pre-operative 6MWD (155 m, versus $232 \mathrm{~m}$ for those operated). Of the patients offered PEA for operable CTEPH, $16 \%(n=72)$ refused surgery. These cases were also more likely to be female $(63 \%)$ and older (age 68 years) and have lower 6MWD $(169 \mathrm{~m})$. It is unknown if this was a coincidence or somehow factored into patient decision. The report does not discuss details regarding the reasons for patient refusal, any details of pre-operative risk discussions between the providers and the patients, or whether patients on the decision fence had the opportunity to visit with the reference centre for direct evaluations and treatment counselling. In the end, the patients who refused PEA had a lower observed survival rate than those who underwent surgery (5-year survival rate of $53 \%$, versus $83 \%$ for those operated), with a rate similar to the cohort deemed not amenable to surgery.

QUADERY et al. [8] acknowledged an important limitation of the report: the case series pre-dated riociguat therapy and balloon pulmonary angioplasty (BPA). Although these now established treatment modalities may have had an impact for the subgroup deemed inoperable, the cases refusing surgery were felt to be operable [12-14]. Currently there are no data supporting riociguat or BPA for the primary treatment of operable CTEPH in lieu of PEA. It is possible, however, that with the availability of approved medical therapy and BPA for inoperable CTEPH, additional patients deemed operable may instead opt for a trial of these modalities over recommended surgery. In a chart review study of PEA-eligible cases from Europe and the USA, $20 \%$ and $19 \%$ of operable cases, respectively, refused PEA [10]. Although the reasons for patient refusal were not mentioned, examples of CTEPH cases not referred initially by surveyed providers for surgical evaluation included 1) "only if drug therapy does not work I would consider surgery", and 2) "surgery is too risky/high mortality". In truth, experienced PEA centres are achieving the lowest mortality rates ever observed $(2.2-4.7 \%)$ [5, 15], and drug therapy is recommended for inoperable cases only following surgical evaluation, not before [7].

Another important limitation not discussed in the report by QUADERY et al. [8] is that of determining surgical candidacy. Although each case underwent a multidisciplinary evaluation process, the assessment by the prospective operating surgeon was done remotely. In addition to the 72 cases refusing surgery prior to meeting the surgeon, the $36 \%(n=63)$ of the cases deemed technically operable but not suitable for surgery may have reached a different operability conclusion had they been directly evaluated by an expert surgical centre [16]. Especially in such potentially challenging cases, the subjectivity of operability assessment would benefit from direct patient evaluation and counselling by the operating surgeon.

As the field is evolving with more complex diagnostics and multimodal therapies, the urgency is now for improving CTEPH treatment education. The information gap is not solely with patients; this would be an incomplete conclusion of the results presented by QUADERY et al. [8]. Patients are influenced by what they hear and see from their trusted medical providers $[17,18]$. The medical community, and in particular those specialists often making the initial diagnosis of CTEPH, needs ongoing education and better understanding of CTEPH treatment. With that, hopefully more patients with operable CTEPH will make the correct healthcare decision.

Conflict of interest: N.K. Kim reports personal fees from Actelion and Bayer (speaker bureau, steering committee and consultant fees), personal fees from Merck (consultant fees), support from the International CTEPH Association (as a board member), and personal fees from CTEPH.com (as a board member), outside the submitted work. E. Mayer reports personal fees from Actelion, Bayer and MSD (speaker's and consulting fees), and from Pfizer (speaker's fees), during the conduct of the study.

\section{References}

1 Riedel M, Stanek V, Widimsky J, et al. Longterm follow-up of patients with pulmonary thromboembolism. Late prognosis and evolution of hemodynamic and respiratory data. Chest 1982; 81: 151-158.

2 Yi ES, Kim H, Ahn H, et al. Distribution of obstructive intimal lesions and their cellular phenotypes in chronic pulmonary hypertension. A morphometric and immunohistochemical study. Am J Respir Crit Care Med 2000; 162: $1577-1586$.

3 Dorfmüller P, Günther S, Ghigna MR, et al. Microvascular disease in chronic thromboembolic pulmonary hypertension: a role for pulmonary veins and systemic vasculature. Eur Respir J 2014; 44: 1275-1288.

4 Moser KM, Bloor CM. Pulmonary vascular lesions occurring in patients with chronic major vessel thromboembolic pulmonary hypertension. Chest 1993; 103: 685-692. 
5 Mayer E, Jenkins D, Lindner J, et al. Surgical management and outcome of patients with chronic thromboembolic pulmonary hypertension: results from an international prospective registry. J Thorac Cardiovasc Surg 2011; 141: 702-710.

6 Archibald CJ, Auger WR, Fedullo PF, et al. Long-term outcome after pulmonary thromboendarterectomy. Am J Respir Crit Care Med 1999; 160: 523-528.

7 Galiè N, Humbert M, Vachiery JL, et al. 2015 ESC/ERS Guidelines for the diagnosis and treatment of pulmonary hypertension. Eur Heart J 2016; 37: 67-119.

8 Quadery SR, Swift AJ, Billings CG, et al. The impact of patient choice on survival in chronic thromboembolic pulmonary hypertension. Eur Respir J 2018; 52: 1800589.

9 Pepke-Zaba J, Delcroix M, Lang I, et al. Chronic thromboembolic pulmonary hypertension (CTEPH): results from an international prospective registry. Circulation 2011; 124: 1973-1981.

10 Gall H, Preston IR, Hinzmann B, et al. An international physician survey of chronic thromboembolic pulmonary hypertension management. Pulm Circ 2016; 6: 472-482.

11 Delcroix M, Lang I, Pepke-Zaba J, et al. Long-term outcome of patients with chronic thromboembolic pulmonary hypertension: results from an international prospective registry. Circulation 2016; 133: 859-871.

12 Ghofrani HA, D'Armini AM, Grimminger F, et al. Riociguat for the treatment of chronic thromboembolic pulmonary hypertension. N Engl J Med 2013; 369: 319-329.

13 Simonneau G, D'Armini AM, Ghofrani HA, et al. Predictors of long-term outcomes in patients treated with riociguat for chronic thromboembolic pulmonary hypertension: data from the CHEST-2 open-label, randomised, long-term extension trial. Lancet Respir Med 2016; 4: 372-380.

14 Kawakami T, Ogawa A, Miyaji K, et al. Novel angiographic classification of each vascular lesion in chronic thromboembolic pulmonary hypertension based on selective angiogram and results of balloon pulmonary angioplasty. Circ Cardiovasc Interv 2016; 9: e003318.

15 Madani MM, Auger WR, Pretorius V, et al. Pulmonary endarterectomy: recent changes in a single institution's experience of more than 2,700 patients. Ann Thorac Surg 2012; 94: 97-103.

16 Jenkins DP, Biederman A, D'Armini AM, et al. Operability assessment in CTEPH: lessons from the CHEST-1 study. J Thorac Cardiovasc Surg 2016; 152: 669-674.

17 Loewenstein G. Projection bias in medical decision making. Med Decis Making 2005; 25: 96-105.

18 Redelmeier DA, Rozin P, Kahneman D. Understanding patients' decisions. Cognitive and emotional perspectives. JAMA 1993; 270: 72-76. 